\title{
Activation of Group II Metabotropic Glutamate Receptors Inhibits the Discriminative Stimulus Effects of Alcohol via Selective Activity Within the Amygdala
}

\author{
Reginald Cannady', ${ }^{1,2}$ Julie JM Grondin', Kristen R Fisher', Clyde W Hodge ${ }^{1,2,3,4}$ and Joyce Besheer*,1,2,3 \\ 'Bowles Center for Alcohol Studies, University of North Carolina at Chapel Hill, Chapel Hill, NC, USA; ${ }^{2}$ Curriculum in Neurobiology, University of \\ North Carolina at Chapel Hill, Chapel Hill, NC, USA; ${ }^{3}$ Department of Psychiatry, University of North Carolina at Chapel Hill, Chapel Hill, NC, USA; \\ ${ }^{4}$ Department of Pharmacology, University of North Carolina at Chapel Hill, Chapel Hill, NC, USA
}

\begin{abstract}
Metabotropic glutamate receptor subtypes ( $\mathrm{mGlu2} / 3$ ) regulate a variety of alcohol-associated behaviors, including alcohol reinforcement, and relapse-like behavior. To date, the role of $\mathrm{mGlu} 2 / 3$ receptors in modulating the discriminative stimulus effects of alcohol has not been examined. Given that the discriminative stimulus effects of drugs are determinants of abuse liability and can influence drug seeking, we examined the contributions of $\mathrm{mGlu2/3}$ receptors in modulating the discriminative stimulus effects of alcohol. In male Long-Evans rats trained to discriminate between alcohol $(\mathrm{I} / \mathrm{gg}, \mathrm{IG})$ and water, the $\mathrm{mGlu} 2 / 3$ agonist LY379268 (0.3- $10 \mathrm{mg} / \mathrm{kg})$ did not produce alcohollike stimulus effects. However, pretreatment with LY379268 ( I and $3 \mathrm{mg} / \mathrm{kg}$; in combination with alcohol) inhibited the stimulus effects of alcohol ( $\mathrm{g} / \mathrm{kg})$. Systemic LY379268 (3 mg/kg, i.p.) was associated with increases in neuronal activity within the amygdala, but not the nucleus accumbens, as assessed by c-Fos immunoreactivity. Intra-amygdala activation of mGlu2/3 receptors by LY379268 (6 $\mu \mathrm{g})$ inhibited the discriminative stimulus effects of alcohol, without altering response rate. In contrast, intra-accumbens LY379268 (3 $\mu$ g) profoundly reduced response rate; however, at lower LY379268 doses $(0.3,1 \mu \mathrm{g})$, the discriminative stimulus effects of alcohol and response rate were not altered. These data suggest that amygdala $\mathrm{mGlu2/3}$ receptors have a functional role in modulating the discriminative stimulus properties of alcohol and demonstrate differential motor sensitivity to activation of $\mathrm{mGlu2/3}$ receptors in the amygdala and the accumbens. Understanding the neuronal mechanisms that underlie the discriminative stimulus effects of alcohol may prove to be important for future development of pharmacotherapies for treating alcoholism.

Neuropsychopharmacology (20II) 36, 2328-2338; doi:I 0.1038/npp.20 I I.I2I; published online 6 July 201 I
\end{abstract}

Keywords: drug discrimination; discriminative stimulus; ethanol; glutamate; mGluR2/3; amygdala

\section{INTRODUCTION}

Drugs of abuse share the common attribute that they produce distinct subjective or interoceptive effects. In both humans and animals, these interoceptive drug effects can serve as discriminative stimuli, such that the subject uses these interoceptive cues to distinguish between drug and non-drug conditions. In addition to reinforcement processes, these discriminative stimulus effects represent a major controlling process of drug seeking behavior (Stolerman, 1992; Wise et al, 2008). To date, there is a growing interest in the role of metabotropic glutamate receptors, subtypes 2 and 3 (mGlu2/3), in modulating drug taking and seeking behavior. For example, systemic admin-

*Correspondence: Dr J Besheer, Bowles Center for Alcohol Studies, University of North Carolina at Chapel Hill, Thurston-Bowles Building; CB \#7178, Chapel Hill, NC 27599, USA, Tel: + I 919843 4389; Fax: + | 919966 5679, E-mail: jbesheer@med.unc.edu

Received 4 March 2011; revised 4 May 2011; accepted 6 June 201। istration of mGlu2/3 receptor agonists has been shown to inhibit cocaine and nicotine self-administration (Baptista et al, 2004; Adewale et al, 2006; Liechti et al, 2007). In relation to alcohol, systemic mGlu2/3 receptor activation can reduce alcohol self-administration (Backstrom and Hyytia, 2005; Sidhpura and Weiss, 2010; but see Rodd et al, 2006) and relapse-like behavior (Rodd et al, 2006; Zhao et al, 2006; Sidhpura and Weiss, 2010). However, the potential role of mGlu2/3 receptors in regulating the discriminative stimulus effects of alcohol has not been examined.

mGlu2/3 receptors are members of the group II family of mGluRs. These $\mathrm{G}_{\mathrm{i}}$-coupled receptors function as autoreceptors; regulating presynaptic neurotransmitter release (Baskys and Malenka, 1991; Liu et al, 1993; Macek et al, 1996; Marek et al, 2000; Molinaro et al, 2009; Farazifard and $\mathrm{Wu}, 2010)$. As such, activation of mGlu2/3 receptors decreases the synaptic availability of glutamate, allowing for 'refinement' of glutamatergic neurotransmission (Schoepp, 2001; Pinheiro and Mulle, 2008). Given the functional role of $\mathrm{mGlu} 2 / 3$ receptors in modulating 
glutamate release and that the discriminative stimulus effects of alcohol are generally characterized by processes that reduce/inhibit glutamatergic neurotransmission (Kostowski and Bienkowski, 1999), such that $N$-methyl-Daspartic acid (NMDA) antagonists and $\gamma$-aminobutyric acid type $\mathrm{A}\left(\mathrm{GABA}_{\mathrm{A}}\right)$-positive modulators produce alcohol-like discriminative stimulus effects (Jarbe and McMillan, 1983; Schechter et al, 1993; Ator et al, 1993; Bienkowski et al, 1997; Hundt et al, 1998; Grant et al, 2000; Shelton and Grant, 2002; Vivian et al, 2002; Helms et al, 2009), we hypothesized that mGlu2/3 receptors may have a modulatory role in the expression of the discriminative stimulus effects of alcohol. Further support for this hypothesis comes from studies showing that mGlu2/3 receptors are highly expressed in limbic brain regions (Petralia et al, 1996; Ohishi et al, 1998; Ferraguti and Shigemoto, 2006) known to modulate the discriminative stimulus effects of alcohol, such as the nucleus accumbens and the amygdala (Hodge and Aiken, 1996; Hodge and Cox, 1998; Hodge et al, 2001; Besheer et al, 2003).

Accordingly, the purpose of this study was to examine the role of $\mathrm{mGlu} 2 / 3$ receptors in modulating the discriminative stimulus effects of alcohol. Male Long-Evans rats were trained to discriminate between a moderate dose of alcohol $(1 \mathrm{~g} / \mathrm{kg})$ and water administered orally by gavage (IG) on a well-characterized two lever drug discrimination task. We first examined whether systemic pharmacological activation of mGlu2/3 receptors by LY379268, a selective mGlu2/3 receptor agonist (Monn et al, 1999), produces alcohol-like discriminative stimulus effects and/or modulates the discriminative stimulus effects of alcohol. Next, we sought to identify whether mGlu2/3 receptor activation is associated with changes in neuronal activity in specific brain regions as measured by c-Fos immunoreactivity (IR) using immunohistochemistry techniques. Finally, guided by the anatomical specificity of those results, discriminationtrained rats were implanted with bilateral cannulae aimed at the amygdala and nucleus accumbens (anatomical control) for site-specific LY379268 administration to directly assess the functional role of mGlu2/3 receptor activation within these regions in modulating the expression of the discriminative stimulus effects of alcohol.

\section{MATERIALS AND METHODS}

\section{Animals}

Male Long-Evans rats (Harlan Sprague Dawley, Indianapolis, IN) were individually housed in Plexiglas cages. Before training, male rats were weighed and handled daily. Food intake was restricted to approximately $16 \mathrm{~g}$ of food/day to maintain body weight $(325-340 \mathrm{~g})$. Water was available ad libitum in the home cage unless noted. The colony room was maintained on a 12-h light/dark cycle. Experiments were conducted during the light cycle (between 0800 and 1100 hours). Animals were under continuous care and monitoring by veterinary staff from the Division of Laboratory Animal Medicine at UNC-Chapel Hill. All procedures were conducted in accordance with the NIH Guide to Care and Use of Laboratory Animals and institutional guidelines.

\section{Alcohol Discrimination Training and Testing Procedures}

Lever press training. Rats were trained to lever press on a fixed ratio 1 (FR1) schedule of sucrose $(10 \%(\mathrm{w} / \mathrm{v}))$ reinforcement in operant conditioning chambers (Med Associates, Georgia, VT). A single lever (left or right) was present on alternating training days as the FR schedule was gradually increased to FR10. Alcohol discrimination training began after stabilization of response rates on both levers with $<10 \%$ daily variation in total responses.

Discrimination training. Alcohol $(1 \mathrm{~g} / \mathrm{kg})$ or water was administered IG before daily training sessions (M-F). Immediately following alcohol or water, rats were placed in the chambers for a 10-min timeout period. Next, the house light was illuminated and both levers were introduced, signaling commencement of the 15-min session. Training days varied on a double alternation schedule (water, water, alcohol, alcohol...). Completion of 10 responses on the alcohol-appropriate lever (eg, left lever) resulted in the presentation of the sucrose solution. Likewise, completion of 10 responses on the waterappropriate lever (eg, right lever) resulted in sucrose delivery. Responses on the inappropriate lever were recorded, but produced no programmed consequences. Water- and alcohol-associated levers were randomly assigned and counterbalanced across animals. Testing began when the accuracy criteria were met: the percentage of appropriate lever responses before the first reinforcer, and during the entire session was $>80 \%$ for at least 8 out of the 10 consecutive days.

Testing. Test sessions were similar to training sessions except that they were $2 \mathrm{~min}$ in duration (after 10-min delay), and 10 responses on either lever resulted in sucrose delivery. Reinforcement was delivered to examine the effects of treatments on overall response rates (internal measure of nonspecific motor effects). Test sessions were interspersed with training sessions if performance during $\geqslant 3$ of 4 previous training sessions met accuracy criteria.

\section{Confirmation of Discriminative Stimulus Control By Alcohol}

Cumulative alcohol dose substitution curve. An alcohol dose substitution curve was determined before testing of LY379268 to ensure alcohol stimulus control. Cumulative dosing procedures (Hiltunen and Jarbe, 1989; Hodge et al, 2001; Besheer et al, 2009) were used for all testing sessions (excluding microinjection studies). To determine a cumulative alcohol dose response curve $(0.1,0.3,1.0,1.7 \mathrm{~g} / \mathrm{kg})$, rats initially received $0.1 \mathrm{~g} / \mathrm{kg}$ alcohol and were placed in the chamber for a 10 -min delay period followed by a 2 -min test session. After the session, rats received a subsequent alcohol administration of $0.2 \mathrm{~g} / \mathrm{kg} \quad(0.3 \mathrm{~g} / \mathrm{kg}$ cumulative dose) and another delay/test session. This procedure was repeated with two subsequent administrations of $0.7 \mathrm{~g} / \mathrm{kg}$ alcohol, which are additive to produce the stated dose range. Thus, testing of the entire dose curve was completed in $\sim 48 \mathrm{~min}$. No more than two test sessions were conducted per week. 


\section{Effects of LY379268 Alone and in Combination with Alcohol}

Systemic agonist substitution for alcohol. Cumulative doses of LY379268 (0.3, 1, 3, $10 \mathrm{mg} / \mathrm{kg}$, i.p.; $n=10)$ were tested to determine whether $m G l u 2 / 3$ receptor activation produced alcohol-like stimulus effects. Doses within this range have been reported to be effective at reducing alcohol self-administration and seeking behavior (Backstrom and Hyytia, 2005; Rodd et al, 2006; Sidhpura and Weiss, 2010). Water/alcohol administration was withheld during these tests.

Effects of systemic mGlu2/3 receptor activation on the discriminative stimulus effects of alcohol. At 2 weeks following the agonist substitution test, a cumulative alcohol substitution test $(0.1,0.3,1.0,1.7 \mathrm{~g} / \mathrm{kg})$ was performed to determine whether mGlu2/3 receptor activation altered the discriminative stimulus effects of alcohol. LY379268 (0, 1, $3 \mathrm{mg} / \mathrm{kg}$ ) was administered at $10 \mathrm{~min}$ before the first alcohol dose of the cumulative alcohol substitution test. LY379268 doses were tested according to a randomized within subjects design.

\section{Examination of c-Fos IR in the Amygdala and Nucleus Accumbens}

c-Fos immunohistochemistry. Experimentally naive male Long-Evans rats were divided into two groups and administered saline (i.p.) or LY379268 (3 mg/kg; i.p.; $n=5$ (group). Approximately, at $110 \mathrm{~min}$ after the injection, rats were anesthetized and brains were extracted after transcardial perfusion. Tissue was sliced into $40 \mu \mathrm{m}$ sections and stored $\left(-20^{\circ} \mathrm{C}\right)$ until further processing. Sections were immunolabeled by rabbit anti-c-Fos antibody (1:20000 dilution; Calbiochem) using a biotinylated secondary anti-rabbit antibody conjugated to an avidin-biotin complex (Vector ABC kit, Vector Laboratories). c-Fos-IR was visualized by diaminobenzidine solution (Polysciences, Warrington, PA; see Supplementary Materials and Methods).

Immunohistochemical quantification. c-Fos-IR was visualized using an Olympus CX41 light microscope (Olympus America, Center Valley, PA). IR was quantified with image analysis software (Bioquant Nova; R\&M Biometric, Nashville, TN) using a digital camera (Regita model, QImaging, Burnaby, BC) interfaced to a computer (Dell, Round Rock, TX). The microscope, camera, and software were background corrected and normalized to preset light levels to ensure fidelity of data acquisition. c-Fos-IR pixel count measurements were calculated from a circumscribed field (eg, brain region) and divided by the area of the region and expressed as c-Fos-positive pixels $/ \mathrm{mm}^{2}$. Analysis was conducted by a researcher blind to the treatment conditions. Data were acquired from at least three sections/brain region/animal for c-Fos-IR and analyses were averaged to obtain one value per subject. The regions examined were the amygdala (central nucleus (CeA); basal lateral nucleus (BLA); lateral dorsal nucleus (LaDL); -1.80 to $-2.50 \mathrm{AP}$ ) and nucleus accumbens (shell and core; +1.70 to +1.00 AP; Paxinos and Waton, 1998).
Effects of Intra-Amygdala and Intra-Accumbens mGlu2/3 Receptor Activation on the Discriminative Stimulus Effects of Alcohol

Surgery and drug administration. Stereotaxic surgery was performed in discrimination-trained rats $(n=12)$. Two sets of bilateral guide cannulae (26-gauge; Plastics One, Roanoke, VA) were implanted to terminate $2 \mathrm{~mm}$ above the nucleus accumbens (core) and the amygdala (CeA). The coordinates for the nucleus accumbens and amygdala were $\mathrm{AP}+1.7, \mathrm{ML}+1.5 \mathrm{~mm}, \mathrm{DV}-5.5 \mathrm{~mm}$, and $\mathrm{AP}-1.9, \mathrm{ML}+$ $4.2,-6.5 \mathrm{DV}$ (from skull), respectively (Paxinos and Waton, 1998). We made no attempt to functionally distinguish specific sub-nuclei of the accumbens (eg, core vs shell) or amygdala (eg, CeA, BLA, or LaDL) based on evidence that suggests that the distance of drug diffusion after microinjection could possibly be larger than the distance between each sub-nuclei (Perez de la Mora et al, 2006). Rats were allowed 1 week for recovery before resuming alcohol discrimination training.

Site-specific bilateral microinjections were made with $1.0 \mu \mathrm{l}$ Hamilton syringes connected to 33-gauge injectors (Plastics One, Roanoke, VA) extending $2 \mathrm{~mm}$ below the guide cannulae. A pump (Harvard Apparatus, Natick, MA) delivered a volume of $0.5 \mu \mathrm{l} /$ side for $1 \mathrm{~min}$. The injector remained in place for $1.5 \mathrm{~min}$ after injections to allow for diffusion. LY379268 was micro-infused into the amygdala $(0,0.3,3,6 \mu \mathrm{g} / 0.5 \mu \mathrm{l} / \mathrm{side})$ or nucleus accumbens $(0,0.3,1$, $3 \mu \mathrm{g} / 0.5 \mu \mathrm{l} / \mathrm{side})$. After the diffusion period, rats received a single alcohol dose $(1 \mathrm{~g} / \mathrm{kg}, \mathrm{IG})$ and were placed in the chamber for a test session (similar to the systemic dosing test sessions, with the exception that rats experienced a single test). For the first four tests, all rats received a sham injection and a vehicle injection in the nucleus accumbens and a sham injection and vehicle injection in the amygdala. After initial tests, a single LY379268 and alcohol dose $(1 \mathrm{~g} / \mathrm{kg})$ combination was randomly tested in each brain region during each session. Cannulae placements were verified following microinjection experiments (see Supplementary Materials and Methods).

Drugs. Alcohol (95\% (w/v); Pharmco-AAPER, Shelbyville, $\mathrm{KY})$ was diluted in distilled water to $20 \%(\mathrm{v} / \mathrm{v})$ and administered IG. Alcohol volume was varied to achieve doses of $0.1,0.3,1$, and $1.7 \mathrm{~g} / \mathrm{kg}$. $(1 R, 4 R, 5 S, 6 R)-4$-amino-2oxabicyclo[3.1.0] hexane-4,6-dicarboxylic acid (LY379268; Tocris, Ellisville, MI) and was dissolved in $0.9 \%$ saline and injected at a volume of $1 \mathrm{ml} / \mathrm{kg}$ (i.p.). LY379268 is a systemically active potent agonist of group II mGlu receptors and devoid of agonist or antagonist activity at ionotropic glutamate receptors, mGlula, mGlu5a, or mGlu7 receptors (Monn et al, 1999). For microinfusion studies, LY379268 was dissolved in artificial cerebral spinal fluid.

Data analysis. Response accuracy was expressed as a percentage of alcohol-appropriate responses on delivery of the first reinforcer. Response rate (responses/min) was analyzed for the entire session and served as a measure of locomotor ability/drug efficacy. Complete substitution for alcohol was defined as $>80 \%$ alcohol-appropriate responding. Data from rats that did not complete an FR10 during test sessions were excluded from response accuracy 
analysis, but included in the response rate analysis. Response accuracy and response rate data were analyzed by one or two-way repeated measures (RM) analysis of variance (ANOVA) with Tukey post hoc comparisons. c-Fos-IR was analyzed using Student's $t$-tests to compare treatment groups within brain regions. Significance was declared at $p \leqslant 0.05$.

\section{RESULTS}

\section{Confirmation of Discriminative Stimulus Control by Alcohol}

Cumulative alcohol dose substitution curve. For each rat tested in the discrimination experiments, alcohol discriminative stimulus control was evaluated first by testing a range of cumulative alcohol doses before mGlu2/3 receptor agonist testing. Analyses are representative from all rats in each of the three discrimination experiments $(n=22)$. Alcohol-appropriate responding was significantly increased in a dose-dependent manner after cumulative alcohol administration (Figure 1a; $\mathrm{F}(3,60)=38.221, p<0.001$ ), with $1.7 \mathrm{~g} / \mathrm{kg}$ fully substituting $(>80 \%)$ for the alcohol training dose (ie, producing stimulus properties similar to the training dose). The $1.0 \mathrm{~g} / \mathrm{kg}$ alcohol dose (training dose) generally produces $>90 \%$ alcohol-appropriate responding during regular training sessions, but tends to produce roughly $60 \%$ alcohol-appropriate responding during the cumulative dosing procedure (Hodge et al, 2001; Besheer et al, 2010). There were no significant changes in response rate throughout cumulative alcohol testing (Figure 1b; $p=0.076)$.

\section{Effects of LY379268 Alone and in Combination with Alcohol}

Systemic agonist substitution for alcohol. The first experiment was aimed at determining if activation of group II mGlu receptors by LY379268 produced alcohol-like discriminative stimulus effects (ie, alcohol substitution;
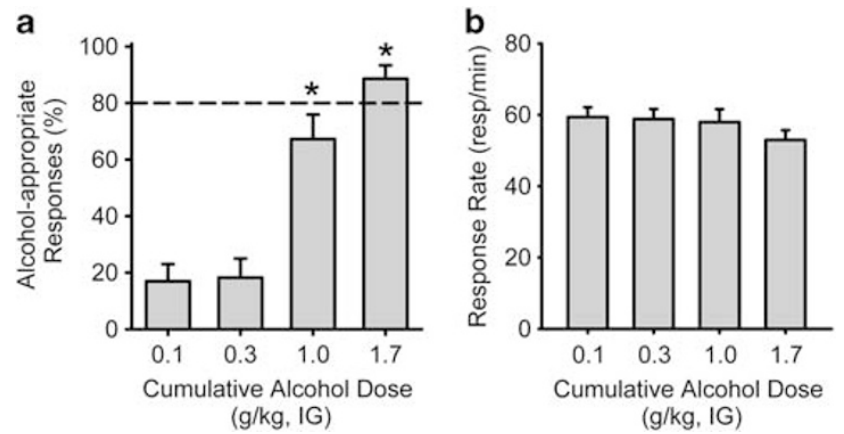

Figure I Confirmation of discriminative stimulus control by alcohol in Long-Evans rats. (a) Responding on the alcohol-appropriate lever during generation of an alcohol substitution curve was significantly increased with each cumulative alcohol dose $(n=22)$, demonstrating that the training procedures established reliable stimulus control. (b) Response rates remained unchanged. Horizontal dashed lines (>80\%) lines denote full substitution for the discriminative stimulus effects of alcohol. Graphed values are expressed as mean \pm SEM. ${ }^{*} p<0.05$ vs $0.1 \mathrm{mg} / \mathrm{kg}$ alcohol (Tukey post hoc).
$>80 \%$ alcohol-appropriate responding). The cumulative LY379268 dose range $(0.3-10 \mathrm{mg} / \mathrm{kg}$, i.p.) did not substitute for alcohol in rats trained to discriminate $1 \mathrm{~g} / \mathrm{kg}$ alcohol from water $(p=0.412$; one-way RM ANOVA). The mean ( \pm SEM) percent alcohol-appropriate responding at each cumulative LY379268 dose was as follows: $1.0 \pm 3.0$ $(0.3 \mathrm{mg} / \mathrm{kg}) ; 0.0 \pm 0.0(1 \mathrm{mg} / \mathrm{kg}) ; 1.0 \pm 3.0$ (3 mg/kg); $2.1 \pm 6.0$ (10 mg/kg). Furthermore, LY379268 also did not alter response rate $(p=0.883$; one-way $\mathrm{RM}$ ANOVA). Mean $( \pm$ SEM) response rate (total responses/min) at each cumulative LY379268 dose was as follows: $56.0 \pm 9.7$ $(0.3 \mathrm{mg} / \mathrm{kg}) ; 53.2 \pm 10.9$ ( $1 \mathrm{mg} / \mathrm{kg}) ; 54.1 \pm 15.8$ (3 mg/kg); $51.7 \pm 14.7(10 \mathrm{mg} / \mathrm{kg})$. These data show that LY379268 does not produce alcohol $(1 \mathrm{~g} / \mathrm{kg})$-like stimulus effects.

Effects of Systemic mGlu2/3 receptor activation on the discriminative stimulus effects of alcohol. The next experiment was conducted to assess the role of $\mathrm{mGlu} 2 / 3$ receptor activation in modulating the discriminative stimulus properties of alcohol. A significant main effect of alcohol dose $(\mathrm{F}(3,27)=60.62, p<0.001)$, and a significant interaction $(\mathrm{F}(6,50)=2.41, p=0.04)$ were observed. A main effect of LY379268 dose was not found $(p=0.31)$. Post hoc comparisons showed a significant reduction in alcoholappropriate responding by LY379268 (1 and $3 \mathrm{mg} / \mathrm{kg}$, i.p.) at $1.0 \mathrm{~g} / \mathrm{kg}$ alcohol $(p<0.001)$, suggesting that $\mathrm{mGlu} 2 / 3$ receptor activation blunted the interoceptive effects of the alcohol training dose (Figure 2a). Overall, LY379268 altered response rate as evidenced by a significant main effect of LY379268 dose $(\mathrm{F}(2,18)=5.48, p=0.01)$; however, none of the doses differed from vehicle, suggesting that the reduction in alcohol-appropriate responding (at $1 \mathrm{~g} / \mathrm{kg}$ alcohol) was not due to nonspecific alterations in response rate. There was also a significant main effect of alcohol dose $(\mathrm{F}(3,27)=3.406, p=0.032)$. These main effects were likely driven by general reductions in response rate at the highest LY379268 and alcohol dose $(3 \mathrm{mg} / \mathrm{kg}$ LY379268+1.7 g/kg
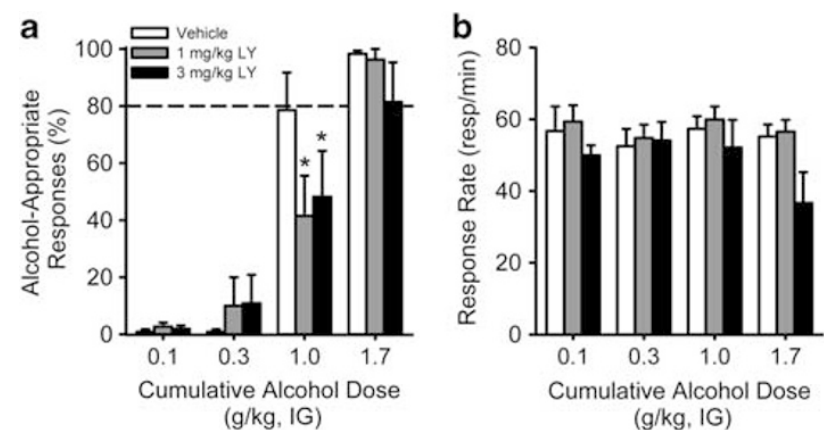

Figure 2 Systemic mGlu2/3 receptor activation by the selective agonist, LY379268, blunts the discriminative stimulus properties of alcohol. (a) Examination of $\mathrm{mGlu} 2 / 3$ receptor modulation of the discriminative stimulus effects of alcohol showed significant decreases in alcoholappropriate responding after treatment with LY379268 (I and $3 \mathrm{mg} / \mathrm{kg}$, i.p.; $n=10$ ) at a cumulative alcohol dose of $1 \mathrm{~g} / \mathrm{kg}$. Note: 7 of the 10 rats responded when given a combination of the highest dose of alcohol ( $1.7 \mathrm{~g} /$ $\mathrm{kg}$ ) and the highest dose of LY379268 (3 mg/kg). (b) Response rate was not significantly decreased by LY379268. These data suggest that activity at $\mathrm{mGlu2} / 3$ receptors has a role in modulating the discriminative stimulus properties of alcohol. Horizontal dashed lines ( $>80 \%$ ) lines denote full substitution for the discriminative stimulus effects of alcohol. Graphed values are expressed as mean \pm SEM. $* p<0.05$ vs vehicle (Tukey post hoc). 
alcohol), as 3 of the 10 rats did not respond; however, a significant interaction was not observed (Figure $2 b$ ).

\section{Examination of c-Fos IR in the Amygdala and Nucleus Accumbens}

Manipulation of metabotropic glutamate receptors has been associated with altered expression of c-Fos (Kaatz and Albin, 1995; Kearney et al, 1997; Zhao et al, 2006; Besheer et al, 2009), a member of a family of immediate early gene transcription factors that is commonly used as a biomarker for mapping neuronal activity (Besheer et al, 2008; Cole et al, 1989; Morgan et al, 1987; Olive et al, 2001). Furthermore, the nucleus accumbens and the amygdala are critically involved in modulating the discriminative stimulus effects of alcohol (Hodge and Aiken, 1996; Hodge and Cox, 1998; Besheer et al, 2003). Therefore, we sought to determine whether the activation of mGlu2/3 receptors is associated with changes in neuronal activity within these regions. Using c-Fos as a marker for neuronal activity, we assessed c-Fos-IR after systemic administration of LY379268. Pretreatment with LY379268 (3 mg/kg, i.p.) produced significant increases in c-Fos IR (positive pixels $/ \mathrm{mm}^{2}$ ) in the BLA (Figure 3a, b and c; $p=0.035$ ), CeA (Figure 3d, e and f; $p=0.014$ ), and LaDL (Figure $3 \mathrm{~g}, \mathrm{~h}$ and $\mathrm{i} ; p=0.028$ ). Interestingly, c-Fos-IR in the core and shell of the nucleus accumbens was not significantly altered by LY379268 (Figure $3 \mathrm{j}, \mathrm{k}$ and $\mathrm{l}$; core $(p=0.875)$, shell
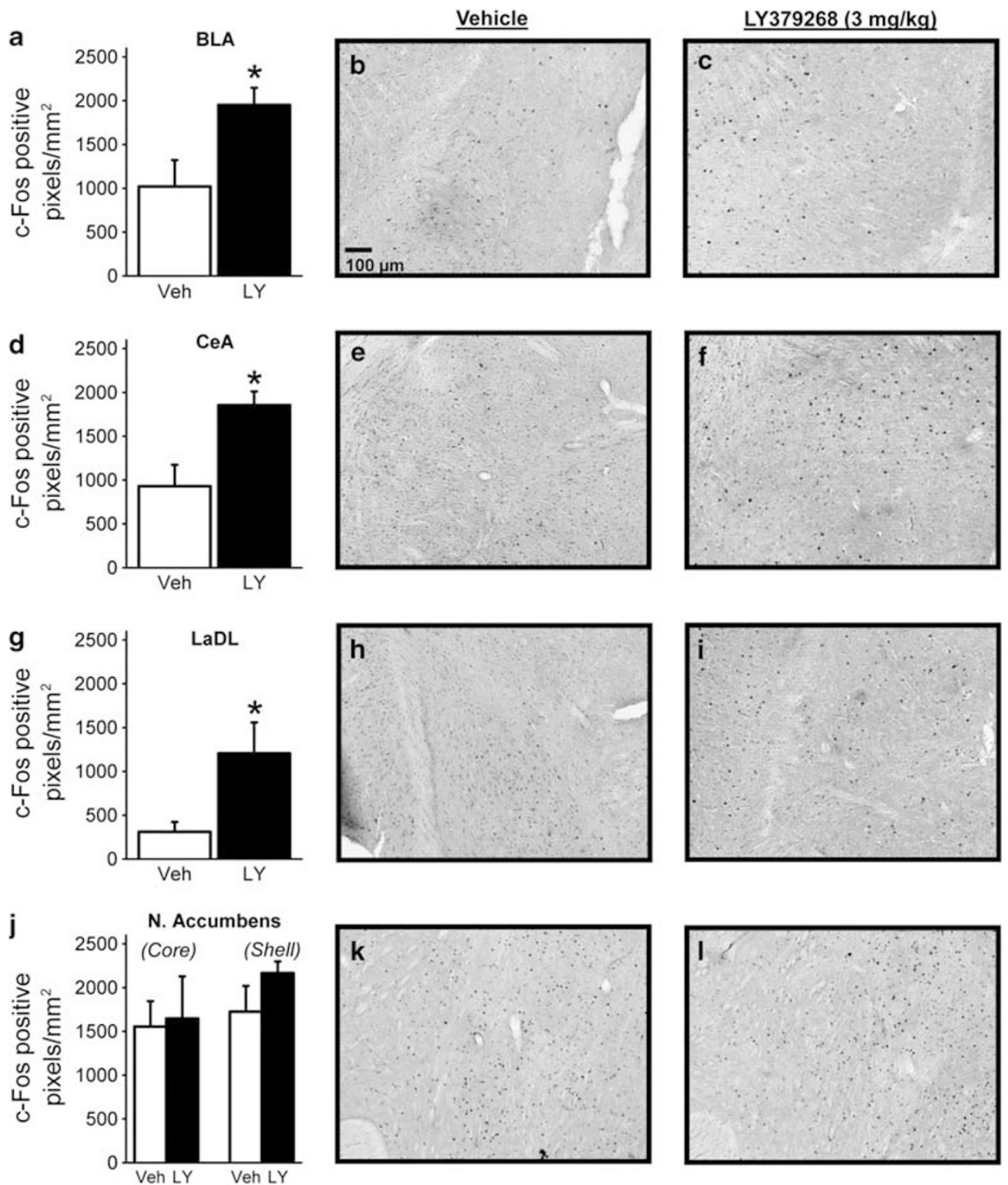

Figure 3 Systemic mGlu2/3 receptor activation increases neuronal activity in specific nuclei of the amygdala. Using c-Fos as a marker for neuronal activity, we examined whether systemic mGlu2/3 receptor activation was associated with activity in limbic brain regions known to mediate the discriminative stimulus effects of alcohol ( $n=5 /$ group). (a, b, and c) The BLA, ( $d$, e, and f) CeA, ( $(\mathrm{g}, \mathrm{h}$, and i) and LaDL nuclei of the amygdala showed significant increases c-Fos-IR, suggesting an increase in neural activity after treatment with LY379268. In contrast, (j, k, and I) the nucleus accumbens core and shell were not significantly altered by LY379268 (3 mg/kg, i.p.) treatment as measured by c-Fos IR. These data suggest that mGlu2/3 receptor-mediated activity within the amygdala may be contributing to modulation of the discriminative stimulus effects of alcohol. Representative photomicrographs $(\times 10)$ are of c-Fos-IR after i.p. vehicle (Veh) or LY379268 (LY) administration. Graphed values are expressed as mean \pm SEM. $* p<0.05$ vs vehicle (t-test). 
$(p=0.245))$. These data suggest that the activation of mGlu2/3 receptors is associated with increased neuronal activity within the amygdala but not the nucleus accumbens, and this increased activity may contribute to mGlu2/3 receptor modulation of the discriminative stimulus effects of alcohol.

\section{Effects of Intra-Amygdala and Intra-Accumbens mGlu2/3 Receptor Activation on the Discriminative Stimulus Effects of Alcohol}

Using data observed in the c-Fos IR experiment as a guide for neuroanatomical selectivity, cannulae were implanted in the amygdala and nucleus accumbens (anatomical control) for site-specific microinjection of LY379268 to examine functional and neuroanatomical specificity of mGlu2/3 receptor modulation of the discriminative stimulus effects of alcohol. Intra-amygdala LY379268 $(6 \mu \mathrm{g})$ produced a significant reduction in alcohol-appropriate responding relative to vehicle treatment (Figure $4 \mathrm{a} ; \mathrm{F}(3,25)=4.761$, $p=0.009$ ), and did not alter response rate (Figure $4 \mathrm{~b}$; $p=0.273)$. Figure $4 \mathrm{c}$ illustrates approximate amygdala cannulae placement. In contrast, intra-accumbens infusion of LY379268 $(0-3 \mu \mathrm{g} / 0.5 \mu \mathrm{l} /$ side $)$ did not significantly alter alcohol-appropriate responding (Figure $4 \mathrm{~d} ; p=0.182$ ). It should be noted that only one of the nine rats responded on the alcohol-appropriate lever when the $3 \mu \mathrm{g}$ dose of LY379268 was microinjected into the accumbens, therefore, there is only one value represented for that data point. Accordingly, LY379268 significantly reduced the response rate (Figure 4e; $\mathrm{F}(3,23)=10.881, p<0.001$ ), with significant reductions observed at the highest dose $(3 \mu \mathrm{g})$ relative to vehicle $(p<0.001)$. Figure $4 \mathrm{f}$ illustrates approximate nucleus accumbens cannulae placement. These data suggest that activation of $\mathrm{mGlu} 2 / 3$ receptors in the amygdala, but perhaps not the nucleus accumbens, inhibits the discriminative stimulus effects of alcohol. In addition, these two brain regions show differential sensitivity to the motor impairing effects of LY379268.

\section{DISCUSSION}

These results show for the first time that the group II metabotropic glutamate receptors have a functional role in modulating the discriminative stimulus properties of alcohol. First, we show that systemic mGlu2/3 receptor activation by LY379268 does not produce alcohol-like stimulus effects. Second, systemic LY379268 administration reduced alcohol-appropriate responding, suggesting a blunting of the interoceptive effects of alcohol following
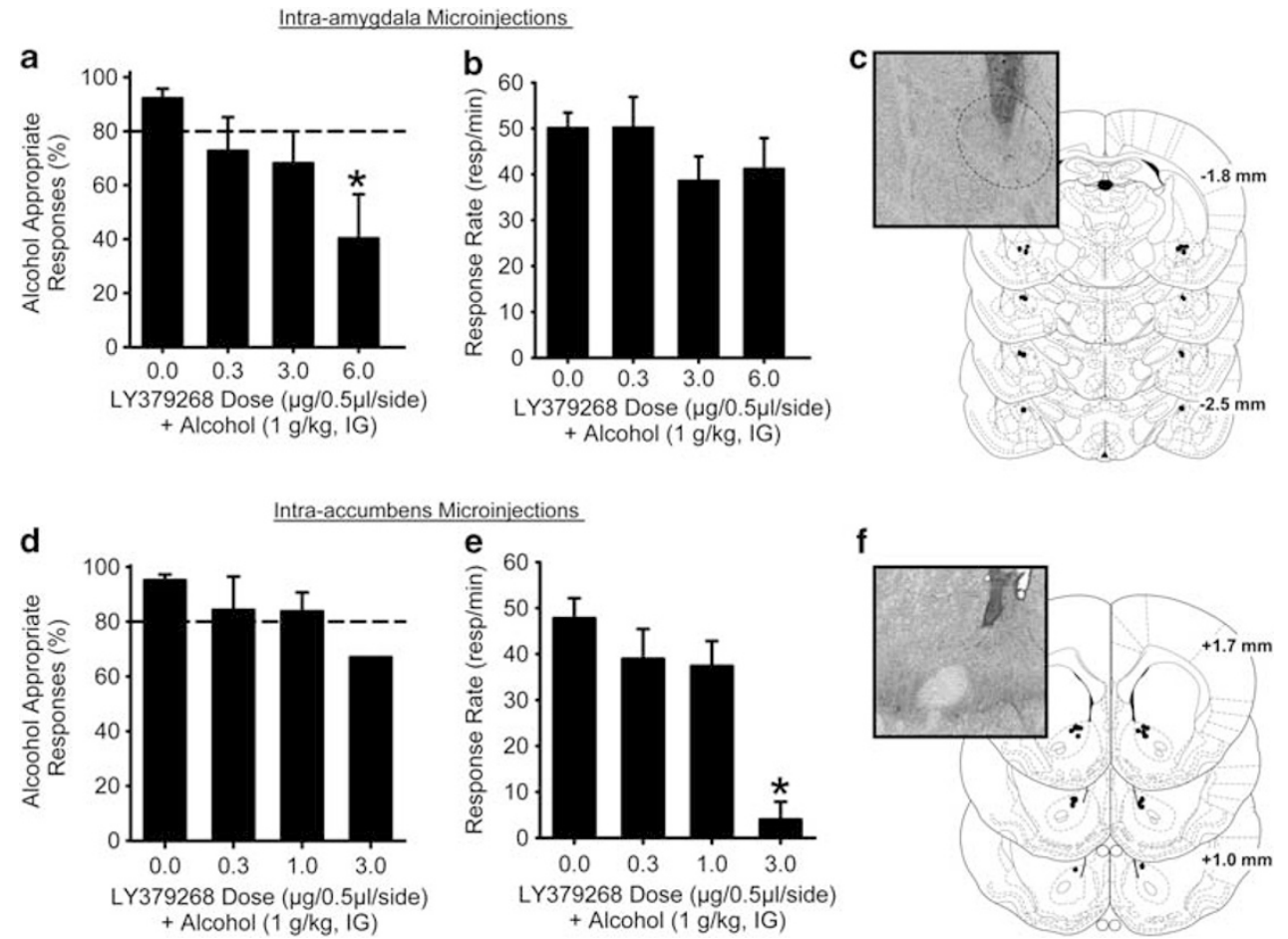

Figure 4 Activation of $m$ Glu2/3 receptors in the amygdala, but not the nucleus accumbens, blunts the discriminative stimulus effects of alcohol. LY379268 was directly microinjected into the amygdala and nucleus accumbens before discrimination testing to directly test the functional role of site-specific mGlu2/3 receptor activation on modulating the discriminative stimulus effects of alcohol. (a) Intra-amygdala $(n=10)$ infusion of LY379268 $(6 \mu \mathrm{g})$ significantly reduced alcohol-appropriate responding, (b) but did not alter response rate, suggesting that the amygdala is a key neuroanatomical structure for mGlu2/3 receptor regulation of the discriminative stimulus properties of alcohol. (c) Representative photomicrograph and illustrations of verified cannulae placements in the amygdala. (d) Contrastingly, intra-accumbens infusion of LY379268 (0-3 $\mu$ g; $n=9)$ did not significantly alter alcohol-appropriate responding. Note: only I of 9 rats responded on the alcohol-appropriate lever at the highest tested dose in the nucleus accumbens ( $3 \mu \mathrm{g})$; (e) a dose that significantly reduced response rate suggesting that $\mathrm{mGlu2} / 3$ receptors in the amygdala but not the nucleus accumbens inhibited the discriminative stimulus effects of alcohol. (f) Representative photomicrograph and Illustrations of verified cannulae placements in the nucleus accumbens. Horizontal dashed lines ( $>80 \%$ ) lines denote full substitution for the discriminative stimulus effects of alcohol. Graphed values are expressed as mean \pm SEM. * $p<0.05$ vs vehicle (Tukey post hoc). 
mGlu2/3 receptor activation. Further, systemic mGlu2/3 receptor activation increased neuronal activity within the amygdala, and not the nucleus accumbens, as measured by c-Fos IR. These findings led us to target $\mathrm{mGlu} 2 / 3$ receptors in the amygdala to determine functional involvement of these receptors in the expression of the discriminative stimulus effects of alcohol. Accordingly, activation of mGlu2/3 receptors by site-specific microinjections of LY379268 in the amygdala reduced alcohol-appropriate responding, confirming functional neuroanatomical control over the discriminative stimulus properties of alcohol. In contrast, intra-accumbens $\mathrm{mGlu} 2 / 3$ receptor activation (anatomical control) did not significantly alter the discriminative stimulus effects of alcohol, but produced a dramatic reduction in response rate (ie, motor impairment) at the highest tested dose. In summary, these data suggest that the amygdala may be a key target region in mGlu $2 / 3$ receptor modulation of the interoceptive effects of alcohol and may be important for the development of mGlu2/3 receptor pharmacotherapeutics for alcohol use disorders.

This study is the first to show that systemic activation of mGlu2/3 receptors does not generalize to the stimulus effects of alcohol, which is consistent with past studies that examined the role of Group I mGlu receptors in modulating the discriminative stimulus effects of alcohol (Besheer and Hodge, 2005; Besheer et al, 2009). These findings are somewhat surprising because of the fact that most compounds that reduce excitatory neurotransmission (ie, NMDA antagonists, $\mathrm{GABA}_{\mathrm{A}}$ agonists) typically substitute for investigator and/or self-administered alcohol in discrimination tasks (Grant and Colombo, 1993; Hodge and Aiken, 1996; Hodge and Cox, 1998; Besheer et al, 2003; Shelton, 2004; Besheer and Hodge, 2005). The difference in the lack of substitution for alcohol may be attributable to interactions between alcohol and the different receptor subtypes. Alcohol alters NMDA and $\mathrm{GABA}_{\mathrm{A}}$ receptor function through direct interaction with these fast action ion channel receptors (Majewska, 1988; Dildy and Leslie, 1989; Weight et al, 1991; Sapp and Yeh, 1998; Criswell et al, 2003). In contrast, mGlu receptors signal through slower intricate G-protein signaling cascades that are well characterized for their relatively modest role in modulating excitatory neurotransmission (Ferraguti and Shigemoto, 2006), allowing for modulation of alcohol effects without generalizing to the stimulus effects of alcohol. Future experimentation examining the role of other mGlu receptor subtypes in alcohol discrimination will be required to validate this hypothesis. It could also be argued that the LY379268 doses tested were not high enough to elicit alcohol-like stimulus effects because there were no changes in behavior observed across tested doses. Indeed, the highest dose did not significantly alter response rate (Figure 2b), but acute doses of LY379268 higher than $10 \mathrm{mg} / \mathrm{kg}$ produce profound motor impairing effects (Cartmell et al, 2000) and may have nonspecific actions at other receptors (Monn et al, 1999; Seeman and Guan, 2008; but see Fell et al, 2009; Zysk et al, 2011), which would potentially complicate the interpretation of results; therefore, higher doses were not tested in this study.

By contrast, when tested in combination with alcohol, systemic administration of LY379268 significantly reduced alcohol-appropriate responding by nearly $50 \%$ without altering the rate of responding, suggesting that activation of mGlu2/3 receptors blunts the interoceptive effects of alcohol. Several studies have shown that systemic administration of $\mathrm{mGlu} 2 / 3$ receptor agonists reduce the reinforcing effects of alcohol and relapse-like behavior in rodents (Backstrom and Hyytia, 2005; Rodd et al, 2006; Sidhpura and Weiss, 2010). This study presents a possible behavioral mechanism that may account, in part, for the efficacy of such compounds in modifying alcohol-drinking behaviors in animal models. That is, reported reductions in alcohol self-administration may be related to alterations in the interoceptive effects of the self-administered/consumed alcohol. It will be interesting for future experiments to directly address this possibility. Interestingly, systemic LY379268 did not reduce alcohol-appropriate responding at a $1.7 \mathrm{~g} / \mathrm{kg}$ dose of alcohol. Alcohol has actions at multiple cellular and molecular targets (Vengeliene et al, 2008), therefore, it is possible that a higher dose of alcohol may further stimulate other receptor or signaling systems, thereby reducing the efficacy of $m$ Glu $2 / 3$ receptor activation in blunting the discriminative stimulus effects of a higher dose of alcohol (Grant, 1999). Further, given that these animals had considerable exposure to the alcohol-training dose $(1 \mathrm{~g} / \mathrm{kg})$, exposure to higher alcohol doses could produce stronger stimulus effects that are more difficult to alter with pharmacological manipulation. Future studies using a higher alcohol-training dose (ie, $2 \mathrm{~g} / \mathrm{kg}$ ) may reveal differences in mGlu2/3 receptor modulation across different alcohol doses.

In an effort to identify neuroanatomical involvement of mGlu2/3 receptors in modulating the interoceptive effects of alcohol, we assessed IR of the early immediate gene transcription factor, c-Fos, as an index of neuronal activity to examine response of limbic brain regions following mGlu2/3 receptor agonist administration. Our focus was on the nucleus accumbens and amygdala given that these are two primary regions known to regulate the discriminative stimulus effects of alcohol (Hodge and Aiken, 1996; Hodge and Cox, 1998; Hodge et al, 2001; Besheer et al, 2003). We showed that systemic LY379268 pretreatment increased c-Fos IR in sub-nuclei of the amygdala, with no change in neuronal activity in the nucleus accumbens of naive rats. These findings are consistent with those of Zhao et al. (2006) after systemic administration of LY379268 in Wistar rats. The observation of increased c-Fos IR after systemic administration seems paradoxical given that a compound that reduces overall glutamate activity and cellular excitability, such as LY379268, would be predicted to decrease neuronal activity. These data suggest that LY379268 may be acting through a postsynaptic mechanism or by interacting with GABA neurons to induce changes in neuronal activity. As such, an explanation for our findings of increased c-Fos IR in the amygdala following systemic LY379268 administration is that $\mathrm{mGlu} 2 / 3$ receptor activation may be altering neuronal activity through a postsynaptic mechanism, whereby activation of postsynaptic mGlu2/3 receptors reduces excitatory neurotransmission. Alternatively, LY379268 could be inducing disinhibition (or reducing GABA inhibition) by reducing glutamate release into synapses that signal through a network of GABAergic interneurons that regulate excitatory neurotransmission within the amygdala. Indeed, systemic administration of a 
structurally similar mGlu2/3 receptor agonist (LY354740) has been shown to induce c-Fos expression in GABAergic neurons (Swanson et al, 2005). Whether the two mGlu2/3 receptor subtypes differentially mediate cellular excitability among different neuronal cell types has yet to be investigated. Regardless of the underlying mechanism, our finding demonstrates that sub-nuclei of the amygdala show a response to $\mathrm{mGlu} 2 / 3$ receptor activation, and also suggests a possible anatomical target for the modulatory effects of mGlu2/3 receptor activation on the expression of the discriminative stimulus effects of alcohol.

Functional involvement of intra-amygdala mGlu2/3 receptors was confirmed as activation of these receptors inhibited expression of the discriminative stimulus effects of alcohol $(1 \mathrm{~g} / \mathrm{kg})$. Interestingly, mGlu2/3 receptor activation in the nucleus accumbens did not alter alcoholappropriate responding, except at a dose that produced a profound reduction in response rate (see later). This functional brain regional dissociation is reflected in the c-Fos-IR findings, in which systemic LY379268 treatment increased neuronal activity in the amygdala but not the nucleus accumbens. This data pattern suggests that amygdala-specific activation of $\mathrm{mGlu} 2 / 3$ receptors reduces sensitivity to the interoceptive cues of alcohol. An explanation for this reduction in sensitivity is that intra-amygdala mGlu2/3 receptor activation resulted in excitation (as discussed above) that blunted the interoceptive effects of the alcohol or interacted with the alcohol to make it less 'alcohol-like'. This could also explain the reduction in alcohol-appropriate responding following systemic LY379268 administration, and is consistent with c-Fos activation in the amygdala. Further, the reductions in alcohol-appropriate responding following systemic administration may be modulated, at least in part, by mGlu2/3 receptors in the amygdala given the similar data pattern after mGlu2/3 receptors administration directly into this region, and not the nucleus accumbens. It is interesting that the highest dose of LY379268 $(6 \mu \mathrm{g})$ was necessary to reduce alcohol-appropriate responding. This dose is indeed higher than that previously reported in microinjection studies using LY379268 (Besheer et al, 2010; Uejima et al, 2007). It may be that repeated alcohol exposure, as used in the present study, induces changes in mGlu2/3 receptor density particularly within the amygdala, thus requiring a higher dose of the agonist to alter behavior. Alternatively, this high localized dose of LY379268 may have had off-target actions at other receptors such as dopamine (D2) receptors (Seeman and Guan, 2008; but see Fell et al, 2009).

An alternative explanation to decreased sensitivity to the interoceptive effects of alcohol is that mGlu2/3 receptor activation interfered with the expression of the learned association. That is, the interoceptive effects of alcohol serve as a discriminative stimulus when the animal has learned that the drug state sets the occasion on which responses on a specific lever are reinforced. Therefore, mGlu2/3 receptor activation may have interfered with the expression of the learned association in the amygdala, but not the nucleus accumbens. Indeed, the amygdala has been well characterized for its role in conditioned associations (Gallagher and Holland, 1994; LeDoux, 2003; Maren, 2005; Zimmerman et $a l, 2007)$, and mounting evidence suggests that this region has an important role in modulating associations between drugs of abuse and stimuli such as internal or environmental cues (Schroeder et al, 2008; See et al, 2003; Theberge et al, 2010). It will be interesting for future experiments to examine the expression and function of mGlu2/3 receptors in the amygdala during different stages of discrimination learning (ie, acquisition $v s$ maintenance) to determine whether learning the discrimination induces changes in $\mathrm{mGlu} 2 / 3$ receptors.

In addition to differential brain regional c-Fos response to mGlu2/3 receptor activation, and functional involvement in the expression of the discriminative stimulus effects of alcohol, the amygdala, and nucleus accumbens also demonstrated differential sensitivity to the motor impairing effects of LY379268. That is, a lower LY379268 dose $(3 \mu \mathrm{g})$ caused profound reductions in response rate when injected into the nucleus accumbens, whereas the amygdala was relatively insensitive to motor impairing effects as a twofold higher dose $(6 \mu \mathrm{g})$ did not alter response rate. Previous work has shown motor-impairing effects after systemic mGlu2/3 receptor agonist administration (Cartmell et al, 2000; Winter et al, 2004; Backstrom and Hyytia, 2005) and intra-accumbens administration (Besheer et al, 2010). Taken together, these data suggest that the nucleus accumbens may have a contributing role in the reported motor impairing effects induced by mGlu2/3 receptor agonists. Interestingly, in this study, systemically administered LY379268 did not alter response rate or c-Fos IR when administered alone. These results are in contrast to the significant motor impairment evident following intraaccumbens administration of LY379268, suggesting dissociation between global glutamatergic pathways or neural circuits that may be affected following systemically and those specifically altered following intra-accumbens administration of the mGlu2/3 receptor agonist. In addition, this differential sensitivity to the motor impairment following systemic and local administration of LY379268 and that of the nucleus accumbens and the amygdala may be attributable to reduced activity from nucleus accumbens efferent projections to the globus pallidus, a key neuroanatomical structure for coordinated locomotor function (Mogenson et al, 1983).

This study shows that the interoceptive effects of a moderate alcohol dose are blunted by activation of mGlu2/3 receptors in the amygdala and that mGlu2/3 receptor activation does not produce alcohol-like effects. Although the specific interaction between interoceptive effects/subjective effects of drugs to reinforcement processes is not yet known, it is interesting to note that mGlu2/3 receptor activation reduces alcohol self-administration (Backstrom and Hyytia, 2005). The lack of substitution for alcohol following mGlu2/3 receptor activation in our study suggests that reported reductions in self-administration are likely not due to the agonist producing alcohol-like effects, and the possibility exists that mGlu2/3 receptor activation may blunt the interoceptive effects of the consumed alcohol. Interestingly, previous work has shown no specific changes in alcohol self-administration behavior following mGlu2/3 receptor activation in the nucleus accumbens (Besheer et al, 2010). This is consistent with findings in this work showing lack of intra-accumbens involvement of $\mathrm{mGlu} 2 / 3$ receptors in modulating the interoceptive effects of alcohol. 
To date, activation of mGlu2/3 receptors has been shown to reduce drug self-administration, relapse to drug-seeking, as well as inhibit the discriminative stimulus effects of PCP, and LSD (Baptista et al, 2004; Winter et al, 2004; Bossert et al, 2006; Peters and Kalivas, 2006; Lu et al, 2007; Hao et al, 2010; Jin et al, 2010), and as demonstrated by this work, alcohol. As such, mGlu2/3 receptors may be an efficacious target for the development of therapeutics for the treatment of addiction (Kenny and Markou, 2004; Heidbreder and Hagan, 2005). Moreover, mGlu2/3 receptor agonists are also generating interest for their potential role in treating multiple psychiatric disorders (Imre, 2007; Patil et al, 2007; Yasuhara and Chaki, 2010), such as depression and anxiety; two disorders that are often co-morbidly expressed in alcoholics (Schuckit and Hesselbrock, 1994; Hasin et al, 2005). In addition, delineating the specific role of each receptor subtype ( 2 and 3 , separately) would be advantageous for drug development, and with the recent emergence of selective mGlu2 and mGlu3 receptor positive modulators, future work may provide some additional insight to the contributions of activity at mGlu2 or 3 receptors in modulating the discriminative stimulus effects of alcohol and reinforcement processes.

\section{ACKNOWLEDGEMENTS}

This work was supported in part by funds from the National Institutes of Health AA016009 (JB), AA014983 (CWH), ABMRF/The Foundation for Alcohol Research (JB), and by the Bowles Center for Alcohol Studies.

\section{DISCLOSURE}

The authors declare no conflict of interest.

\section{REFERENCES}

Adewale AS, Platt DM, Spealman RD (2006). Pharmacological stimulation of group ii metabotropic glutamate receptors reduces cocaine self-administration and cocaine-induced reinstatement of drug seeking in squirrel monkeys. J Pharmacol Exp Ther 318: 922-931.

Ator NA, Grant KA, Purdy RH, Paul SM, Griffiths RR (1993). Drug discrimination analysis of endogenous neuroactive steroids in rats. Eur J Pharmacol 241: 237-243.

Backstrom P, Hyytia P (2005). Suppression of alcohol selfadministration and cue-induced reinstatement of alcohol seeking by the mGlu2/3 receptor agonist LY379268 and the mGlu8 receptor agonist (S)-3,4-DCPG. Eur J Pharmacol 528: 110-118.

Baptista MA, Martin-Fardon R, Weiss F (2004). Preferential effects of the metabotropic glutamate $2 / 3$ receptor agonist LY379268 on conditioned reinstatement versus primary reinforcement: comparison between cocaine and a potent conventional reinforcer. J Neurosci 24: 4723-4727.

Baskys A, Malenka RC (1991). Agonists at metabotropic glutamate receptors presynaptically inhibit EPSCs in neonatal rat hippocampus. J Physiol 444: 687-701.

Besheer J, Cox AA, Hodge CW (2003). Coregulation of ethanol discrimination by the nucleus accumbens and amygdala. Alcohol Clin Exp Res 27: 450-456.

Besheer J, Grondin JJ, Cannady R, Sharko AC, Faccidomo S, Hodge CW (2010). Metabotropic glutamate receptor 5 activity in the nucleus accumbens is required for the maintenance of ethanol self-administration in a rat genetic model of high alcohol intake. Biol Psychiatry 67: 812-822.

Besheer J, Grondin JJ, Salling MC, Spanos M, Stevenson RA, Hodge CW (2009). Interoceptive effects of alcohol require mGlu5 receptor activity in the nucleus accumbens. $J$ Neurosci 29: 9582-9591.

Besheer J, Hodge CW (2005). Pharmacological and anatomical evidence for an interaction between mGluR5- and GABA(A) alpha1-containing receptors in the discriminative stimulus effects of ethanol. Neuropsychopharmacology 30: 747-757.

Besheer J, Schroeder JP, Stevenson RA, Hodge CW (2008). Ethanol-induced alterations of c-Fos immunoreactivity in specific limbic brain regions following ethanol discrimination training. Brain Res 1232: 124-131.

Bienkowski P, Iwinska K, Stefanski R, Kostowski W (1997). Discriminative stimulus properties of ethanol in the rat: differential effects of selective and nonselective benzodiazepine receptor agonists. Pharmacol Biochem Behav 58: 969-973.

Bossert JM, Gray SM, Lu L, Shaham Y (2006). Activation of group II metabotropic glutamate receptors in the nucleus accumbens shell attenuates context-induced relapse to heroin seeking. Neuropsychopharmacology 31: 2197-2209.

Cartmell J, Monn JA, Schoepp DD (2000). Tolerance to the motor impairment, but not to the reversal of PCP-induced motor activities by oral administration of the mGlu2/3 receptor agonist, LY379268. Naunyn Schmiedebergs Arch Pharmacol 361: 39-46.

Cole AJ, Saffen DW, Baraban JM, Worley PF (1989). Rapid increase of an immediate early gene messenger RNA in hippocampal neurons by synaptic NMDA receptor activation. Nature 340: 474-476.

Criswell HE, Ming Z, Griffith BL, Breese GR (2003). Comparison of effect of ethanol on N-methyl-D-aspartate- and GABA-gated currents from acutely dissociated neurons: absence of regional differences in sensitivity to ethanol. J Pharmacol Exp Ther 304: 192-199.

Dildy JE, Leslie SW (1989). Ethanol inhibits NMDA-induced increases in free intracellular $\mathrm{Ca} 2+$ in dissociated brain cells. Brain Res 499: 383-387.

Farazifard R, Wu SH (2010). Metabotropic glutamate receptors modulate glutamatergic and GABAergic synaptic transmission in the central nucleus of the inferior colliculus. Brain Res 1325: 28-40.

Fell MJ, Perry KW, Falcone JF, Johnson BG, Barth VN, Rash KS et al (2009). In vitro and in vivo evidence for a lack of interaction with dopamine $\mathrm{D} 2$ receptors by the metabotropic glutamate $2 / 3$ receptor agonists $1 \mathrm{~S}, 2 \mathrm{~S}, 5 \mathrm{R}, 6 \mathrm{~S}$-2-aminobicyclo[3.1.0]hexane2,6-bicaroxylate monohydrate (LY354740) and (-)-2-oxa-4aminobicyclo[3.1.0] Hexane-4,6-dicarboxylic acid (LY379268). J Pharmacol Exp Ther 331: 1126-1136.

Ferraguti F, Shigemoto R (2006). Metabotropic glutamate receptors. Cell Tissue Res 326: 483-504.

Gallagher M, Holland PC (1994). The amygdala complex: multiple roles in associative learning and attention. Proc Natl Acad Sci USA 91: 11771-11776.

Grant KA (1999). Strategies for understanding the pharmacological effects of ethanol with drug discrimination procedures. Pharmacol Biochem Behav 64: 261-267.

Grant KA, Colombo G (1993). Discriminative stimulus effects of ethanol: effect of training dose on the substitution of N-methyl-D-aspartate antagonists. J Pharmacol Exp Ther 264: 1241-1247.

Grant KA, Waters CA, Green-Jordan K, Azarov A, Szeliga KT (2000). Characterization of the discriminative stimulus effects of GABA(A) receptor ligands in Macaca fascicularis monkeys under different ethanol training conditions. Psychopharmacology (Berl) 152: 181-188. 
Hao Y, Martin-Fardon R, Weiss F (2010). Behavioral and functional evidence of metabotropic glutamate receptor $2 / 3$ and metabotropic glutamate receptor 5 dysregulation in cocaineescalated rats: factor in the transition to dependence. Biol Psychiatry 68: 240-248.

Hasin DS, Goodwin RD, Stinson FS, Grant BF (2005). Epidemiology of major depressive disorder: results from the National Epidemiologic Survey on Alcoholism and Related Conditions. Arch Gen Psychiatry 62: 1097-1106.

Heidbreder CA, Hagan JJ (2005). Novel pharmacotherapeutic approaches for the treatment of drug addiction and craving. Curr Opin Pharmacol 5: 107-118.

Helms CM, Rogers LS, Grant KA (2009). Antagonism of the ethanol-like discriminative stimulus effects of ethanol, pentobarbital, and midazolam in cynomolgus monkeys reveals involvement of specific GABA(A) receptor subtypes.J Pharmacol Exp Ther 331: 142-152.

Hiltunen AJ, Jarbe TU (1989). Discriminative stimulus properties of ethanol: effects of cumulative dosing and Ro 15-4513. Behav Pharmacol 1: 133-140.

Hodge CW, Aiken AS (1996). Discriminative stimulus function of ethanol: role of GABAA receptors in the nucleus accumbens. Alcohol Clin Exp Res 20: 1221-1228.

Hodge CW, Cox AA (1998). The discriminative stimulus effects of ethanol are mediated by NMDA and GABA(A) receptors in specific limbic brain regions. Psychopharmacology (Berl) 139: 95-107.

Hodge CW, Cox AA, Bratt AM, Camarini R, Iller K, Kelley SP et al (2001). The discriminative stimulus properties of self-administered ethanol are mediated by GABA(A) and NMDA receptors in rats. Psychopharmacology (Berl) 154: 13-22.

Hundt W, Danysz W, Holter SM, Spanagel R (1998). Ethanol and $\mathrm{N}$-methyl-D-aspartate receptor complex interactions: a detailed drug discrimination study in the rat. Psychopharmacology (Berl) 135: $44-51$.

Imre G (2007). The preclinical properties of a novel group II metabotropic glutamate receptor agonist LY379268. CNS Drug Rev 13: 444-464.

Jarbe TU, McMillan DE (1983). Interaction of the discriminative stimulus properties of diazepam and ethanol in pigeons. Pharmacol Biochem Behav 18: 73-80.

Jin X, Semenova S, Yang L, Ardecky R, Sheffler DJ, Dahl R et al (2010). The mGluR2 positive allosteric modulator BINA decreases cocaine self-administration and cue-induced cocaineseeking and counteracts cocaine-induced enhancement of brain reward function in rats. Neuropsychopharmacology 35: 2021-2036.

Kaatz KW, Albin RL (1995). Intrastriatal and intrasubthalamic stimulation of metabotropic glutamate receptors: a behavioral and Fos immunohistochemical study. Neuroscience 66: 55-65.

Kearney JA, Frey KA, Albin RL (1997). Metabotropic glutamate agonist-induced rotation: a pharmacological, FOS immunohistochemical, and $\left[{ }^{14} \mathrm{C}\right]$-2-deoxyglucose autoradiographic study. J Neurosci 17: 4415-4425.

Kenny PJ, Markou A (2004). The ups and downs of addiction: role of metabotropic glutamate receptors. Trends Pharmacol Sci 25: 265-272.

Kostowski W, Bienkowski P (1999). Discriminative stimulus effects of ethanol: neuropharmacological characterization. Alcohol 17: 63-80.

LeDoux J (2003). The emotional brain, fear, and the amygdala. Cell Mol Neurobiol 23: 727-738.

Liechti ME, Lhuillier L, Kaupmann K, Markou A (2007). Metabotropic glutamate $2 / 3$ receptors in the ventral tegmental area and the nucleus accumbens shell are involved in behaviors relating to nicotine dependence. J Neurosci 27: 9077-9085.

Liu YB, Disterhoft JF, Slater NT (1993). Activation of metabotropic glutamate receptors induces long-term depression of GABAergic inhibition in hippocampus. J Neurophysiol 69: 1000-1004.

Lu L, Uejima JL, Gray SM, Bossert JM, Shaham Y (2007). Systemic and central amygdala injections of the $\operatorname{mGluR}(2 / 3)$ agonist LY379268 attenuate the expression of incubation of cocaine craving. Biol Psychiatry 61: 591-598.

Macek TA, Winder DG, Gereau RWt, Ladd CO, Conn PJ (1996). Differential involvement of group II and group III mGluRs as autoreceptors at lateral and medial perforant path synapses. J Neurophysiol 76: 3798-3806.

Majewska MD (1988). Interaction of ethanol with the GABAA receptor in the rat brain: possible involvement of endogenous steroids. Alcohol 5: 269-273.

Marek GJ, Wright RA, Schoepp DD, Monn JA, Aghajanian GK (2000). Physiological antagonism between 5-hydroxytryptamine(2A) and group II metabotropic glutamate receptors in prefrontal cortex. J Pharmacol Exp Ther 292: 76-87.

Maren S (2005). Synaptic mechanisms of associative memory in the amygdala. Neuron 47: 783-786.

Mogenson GJ, Swanson LW, Wu M (1983). Neural projections from nucleus accumbens to globus pallidus, substantia innominata, and lateral preoptic-lateral hypothalamic area: an anatomical and electrophysiological investigation in the rat. J Neurosci 3: 189-202.

Morgan JI, Cohen DR, Hempstead JL, Curran T (1987). Mapping patterns of c-fos expression in the central nervous system after seizure. Science 237: 192-197.

Molinaro G, Traficante A, Riozzi B, Di Menna L, Curto M, Pallottino $S$ et al (2009). Activation of mGlu2/3 metabotropic glutamate receptors negatively regulates the stimulation of inositol phospholipid hydrolysis mediated by 5-hydroxytryptamine2A serotonin receptors in the frontal cortex of living mice. Mol Pharmacol 76: 379-387.

Monn JA, Valli MJ, Massey SM, Hansen MM, Kress TJ, Wepsiec JP et al (1999). Synthesis, pharmacological characterization, and molecular modeling of heterobicyclic amino acids related to $(+)$ 2-aminobicyclo[3.1.0] hexane-2,6-dicarboxylic acid (LY354740): identification of two new potent, selective, and systemically active agonists for group II metabotropic glutamate receptors. J Med Chem 42: 1027-1040.

Ohishi H, Neki A, Mizuno N (1998). Distribution of a metabotropic glutamate receptor, $\mathrm{mGluR} 2$, in the central nervous system of the rat and mouse: an immunohistochemical study with a monoclonal antibody. Neurosci Res 30: 65-82.

Olive MF, Mehmert KK, Nannini MA, Camarini R, Messing RO, Hodge CW (2001). Reduced ethanol withdrawal severity and altered withdrawal-induced c-fos expression in various brain regions of mice lacking protein kinase C-epsilon. Neuroscience 103: 171-179.

Patil ST, Zhang L, Martenyi F, Lowe SL, Jackson KA, Andreev BV et al (2007). Activation of $\mathrm{mGlu} 2 / 3$ receptors as a new approach to treat schizophrenia: a randomized Phase 2 clinical trial. Nat Med 13: 1102-1107.

Paxinos G, Waton C (eds) (1998). The Rat Brain in Stereotaxic Coordinates. Academic Press: London.

Perez de la Mora M, Lara-Garcia D, Jacobsen KX, Vazquez-Garcia M, Crespo-Ramirez M, Flores-Gracia C et al (2006). Anxiolytic-like effects of the selective metabotropic glutamate receptor 5 antagonist MPEP after its intra-amygdaloid microinjection in three different non-conditioned rat models of anxiety. Eur $J$ Neurosci 23: 2749-2759.

Peters J, Kalivas PW (2006). The group II metabotropic glutamate receptor agonist, LY379268, inhibits both cocaine- and foodseeking behavior in rats. Psychopharmacology (Berl) 186: 143-149.

Petralia RS, Wang YX, Niedzielski AS, Wenthold RJ (1996). The metabotropic glutamate receptors, mGluR2 and mGluR3, show unique postsynaptic, presynaptic and glial localizations. Neuroscience 71: 949-976. 
Pinheiro PS, Mulle C (2008). Presynaptic glutamate receptors: physiological functions and mechanisms of action. Nat Rev Neurosci 9: 423-436.

Rodd ZA, McKinzie DL, Bell RL, McQueen VK, Murphy JM, Schoepp DD et al (2006). The metabotropic glutamate $2 / 3$ receptor agonist LY404039 reduces alcohol-seeking but not alcohol self-administration in alcohol-preferring (P) rats. Behav Brain Res 171: 207-215.

Sapp DW, Yeh HH (1998). Ethanol-GABAA receptor interactions: a comparison between cell lines and cerebellar Purkinje cells. $J$ Pharmacol Exp Ther 284: 768-776.

Schechter MD, Meehan SM, Gordon TL, McBurney DM (1993). The NMDA receptor antagonist MK-801 produces ethanol-like discrimination in the rat. Alcohol 10: 197-201.

Schoepp DD (2001). Unveiling the functions of presynaptic metabotropic glutamate receptors in the central nervous system. J Pharmacol Exp Ther 299: 12-20.

Schroeder JP, Spanos M, Stevenson JR, Besheer J, Salling M, Hodge CW (2008). Cue-induced reinstatement of alcoholseeking behavior is associated with increased ERK1/2 phosphorylation in specific limbic brain regions: blockade by the mGluR5 antagonist MPEP. Neuropharmacology 55: 546-554.

Schuckit MA, Hesselbrock V (1994). Alcohol dependence and anxiety disorders: what is the relationship? Am J Psychiatry 151: 1723-1734.

See RE, Fuchs RA, Ledford CC, McLaughlin J (2003). Drug addiction, relapse, and the amygdala. Ann NY Acad Sci 985: 294-307.

Seeman P, Guan HC (2008). Phencyclidine and glutamate agonist LY379268 stimulate dopamine D2High receptors: D2 basis for schizophrenia. Synapse 62: 819-828.

Shelton KL (2004). Substitution profiles of N-methyl-D-aspartate antagonists in ethanol-discriminating inbred mice. Alcohol 34: $165-175$.

Shelton KL, Grant KA (2002). Discriminative stimulus effects of ethanol in C57BL/6J and DBA/2J inbred mice. Alcohol Clin Exp Res 26: 747-757.

Sidhpura N, Weiss F, Martin-Fardon R (2010). Effects of the mGlu2/3 agonist LY379268 and the mGlu5 antagonist MTEP on ethanol seeking and reinforcement are differentially altered in rats with a history of ethanol dependence. Biol Psychiatry 67: 804-811.

Stolerman I (1992). Drugs of abuse: behavioural principles, methods and terms. Trends Pharmacol Sci 13: 170-176.
Swanson CJ, Bures M, Johnson MP, Linden AM, Monn JA, Schoepp DD (2005). Metabotropic glutamate receptors as novel targets for anxiety and stress disorders. Nat Rev Drug Discov 4: 131-144.

Theberge FR, Milton AL, Belin D, Lee JL, Everitt BJ (2010). The basolateral amygdala and nucleus accumbens core mediate dissociable aspects of drug memory reconsolidation. Learn Mem 17: 444-453.

Uejima JL, Bossert JM, Poles GC, Lu L (2007). Systemic and central amygdala injections of the mGluR2/3 agonist LY379268 attenuate the expression of incubation of sucrose craving in rats. Behav Brain Res 181: 292-296.

Vengeliene V, Bilbao A, Molander A, Spanagel R (2008). Neuropharmacology of alcohol addiction. Br J Pharmacol 154: 299-315.

Vivian JA, Waters CA, Szeliga KT, Jordan K, Grant KA (2002). Characterization of the discriminative stimulus effects of $\mathrm{N}$ methyl- D-aspartate ligands under different ethanol training conditions in the cynomolgus monkey (Macaca fascicularis). Psychopharmacology (Berl) 162: 273-281.

Weight FF, Lovinger DM, White G (1991). Alcohol inhibition of NMDA channel function. Alcohol Alcohol Suppl 1: 163-169.

Winter JC, Eckler JR, Rabin RA (2004). Serotonergic/glutamatergic interactions: the effects of mGlu2/3 receptor ligands in rats trained with LSD and PCP as discriminative stimuli. Psychopharmacology (Berl) 172: 233-240.

Wise RA, Wang B, You ZB (2008). Cocaine serves as a peripheral interoceptive conditioned stimulus for central glutamate and dopamine release. PLoS ONE 3: e2846.

Yasuhara A, Chaki S (2010). Metabotropic glutamate receptors: potential drug targets for psychiatric disorders. Open Med Chem J 4: 20-36.

Zhao Y, Dayas CV, Aujla H, Baptista MA, Martin-Fardon R, Weiss F (2006). Activation of group II metabotropic glutamate receptors attenuates both stress and cue-induced ethanolseeking and modulates c-fos expression in the hippocampus and amygdala. J Neurosci 26: 9967-9974.

Zimmerman JM, Rabinak CA, McLachlan IG, Maren S (2007). The central nucleus of the amygdala is essential for acquiring and expressing conditional fear after overtraining. Learn Mem 14: 634-644.

Zysk JR, Widzowski D, Sygowski LA, Knappenberger KS, Spear N, Elmore CS et al (2011). Absence of direct effects on the dopamine D2 receptor by mGluR2/3-selective receptor agonists LY 354740 and LY 379 268. Synapse 65: 64-68.

Supplementary Information accompanies the paper on the Neuropsychopharmacology website (http://www.nature.com/npp) 